\title{
Henoch-Schonlein Purpura with hematochezia in an adult patient
}

\author{
Robin George Manappallil1, Pradeep Kumar², Thushara Anand ${ }^{3}$ \\ ${ }^{1}$ Consultant, ${ }^{3}$ Resident, Department of Internal Medicine, Baby Memorial Hospital, Calicut, Kerala, India, ${ }^{2}$ Senior \\ Consultant, Department of Medical Gastroenterology, Baby Memorial Hospital, Calicut, Kerala, India
}

\section{A B S T R A C T}

Henoch-Schönlein purpura (HSP) is a self-limiting vasculitic disease, commonly seen in children. It is characterized by palpable purpura, arthritis, hematuria and abdominal pain. Hematochezia is an uncommon symptom. The patient being reported is an adult male who presented with vomiting, abdominal pain and hematochezia, followed by appearance of palpable purpura and arthritis. He was diagnosed to have HSP. Hematochezia as one of the initial presentations of HSP in adults is an uncommon scenario.

Key words: Henoch-Schönlein purpura; Vasculitis; Hematochezia; Purpura; Arthritis; Leukocytoclastic vasculitis

Access this article online

Website:

http://nepjol.info/index.php/AJMS

DOI: 10.3126/ajms.v11i4.29139

E-ISSN: 2091-0576

P-ISSN: 2467-9100

Copyright (c) 2020 Asian Journal of Medical Sciences

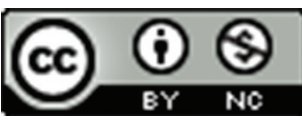

This work is licensed under a Creative Commons Attribution-NonCommercial 4.0 International License.

\section{INTRODUCTION}

Henoch-Schönlein purpura (HSP) is a common form of childhood vasculitis, characterized by palpable purpura, arthritis, colicky abdominal pain and nephritis. It is a multi-systemic IgA mediated small vessel vasculitis, with $90 \%$ patients being younger than 10 years of age. ${ }^{1,2}$ It is an immune mediated response triggered by an infection or by certain drugs; and occurs more often during spring, winter and autumn seasons. ${ }^{3}$ The infections that may precede HSP include group A Streptococcus, infectious mononucleosis, hepatitis, Mycoplasma, Campylobacter, Helicobacter pylori, Yersinia, Shigella, Salmonella, Brucella, Legionella, Parvovirus, Adenovirus, Varicella and Rotavirus. Vaccinations against typhoid, measles, yellow fever and cholera may also lead to the development of HSP. Some of the implicated drugs include penicillin, ampicillin, erythromycin, quinine, losartan and cytarabine.
Majority of the patients present with palpable purpura. Abdominal symptoms as presenting complaint prior to appearance of purpura are uncommon. ${ }^{4}$ Our patient, an adult, has abdominal symptoms of vomiting, pain and hematochezia, followed by purpura and arthritis.

\section{CASE PRESENTATION}

A 20 year old male presented with complaints of severe diffuse abdominal pain, non-projectile vomiting and hematochezia since 2 days. He had consulted a local practioner who prescribed him oral pantoprazole and dicyclomine. The following day he noticed purplish spots all over his upper and lower limbs, and buttocks. On the day of presentation to our hospital, he had painful swelling of right elbow and ankle. He had mild throat pain about 4 days ago, for which he resorted to warm salt water gargle. There was no history of fever. He had not taken any drugs or vaccinations recently. 
On examination, he was conscious and oriented, with stable vitals. His right elbow and ankle joints were swollen and tender, with local rise in temperature. He had purpuric lesions over his upper (Figure 1) and lower (Figure 2) limbs, and gluteal regions. His abdomen was mildly distended, with no tenderness on palpation. Other systemic examinations were normal. There were no signs of meningeal irritation. His throat examination was also normal. From his history and clinical presentation, the probable diagnosis of HSP was made.

His blood investigations showed leucocytosis (12200 cells/cumm with $74 \%$ neutrophils, $20 \%$ lymphocytes, eosinophils $6 \%$ ), elevated erythrocyte sedimentation rate $(30 \mathrm{~mm} /$ hour $)$ and C-reactive protein $(47 \mathrm{mg} / \mathrm{L})$, and hypoalbuminemia $(2.8 \mathrm{mg} / \mathrm{dL})$. Antistreptolysin O (ASO) titers were elevated (440). His renal and liver functions, C3 and C4 complement levels and electrolytes were normal. Anti-nuclear antibody and anti-double stranded DNA were negative. Urine microscopy did not show any haematuria. Epstein-Barr viral capsid antigen IgM and $\operatorname{IgG}$, cytomegalovirus $\operatorname{IgM}$ and $\operatorname{IgG}, \mathrm{HIV}$, hepatitis $B$ virus surface antigen, anti-hepatitis $C$ virus were negative. Blood cultures were sterile. Ultrasound abdomen showed mild to moderate ascites. Contrast enhanced computerized tomography (CT) of the abdomen revealed long segment symmetrical circumferential continuous wall thickening in the ileal loops with moderate luminal

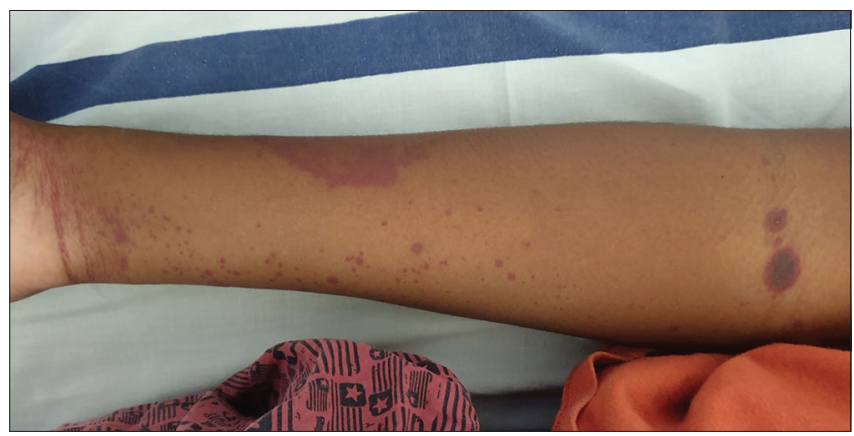

Figure 1: Purpuric lesions over upper limb

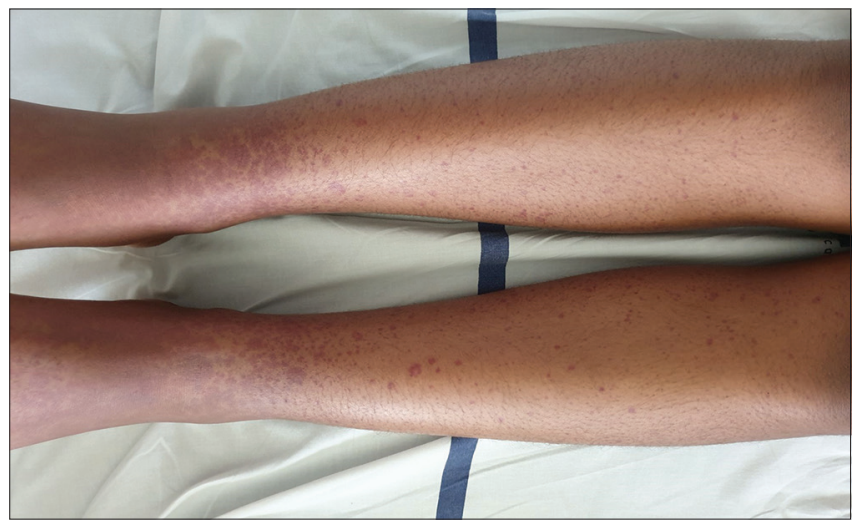

Figure 2: Purpuric lesions over lower limb narrowing, and mild to moderate ascites (Figure 3). Multiple erosions were seen in the rectum, sigmoid, descending, transverse and ascending colon on colonoscopy (Figure 4). Upper gastrointestinal (GI) endoscopy was normal. Histopathologic examination of skin biopsy from the pretibial region showed leukocytoclastic vasculitis, and that from the ileal and colonic mucosa showed edema with mild lymphoplasmacytic infiltration and lymphoid aggregates. Echocardiography and chest Xray were also normal.

He was given pulse doses of methylprednisolone $(20 \mathrm{mg} / \mathrm{kg} /$ day) for 3 days, and was kept nil per oral (NPO) with adequate hydration and intravenous pantoprazole (40 mg twice daily). By day 2 of admission, his arthritis disappeared and purpuric lesions started subsiding. He was started on soft oral diet but had vomiting and abdominal

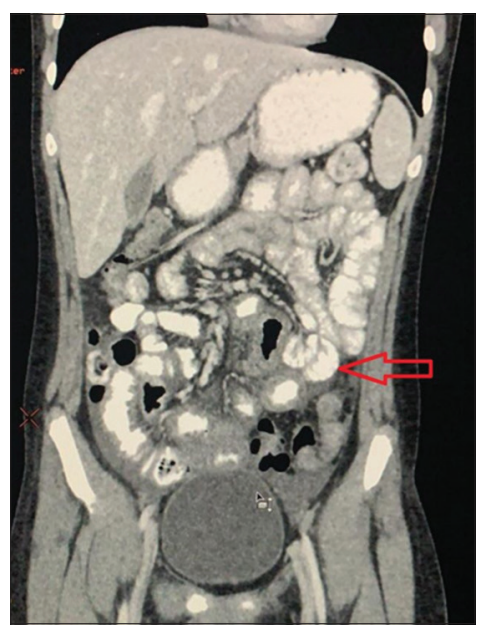

Figure 3: Contrast enhanced CT of the abdomen showing long segment symmetrical circumferential continuous wall thickening in the ileal loops with moderate luminal narrowing and mild to moderate ascites

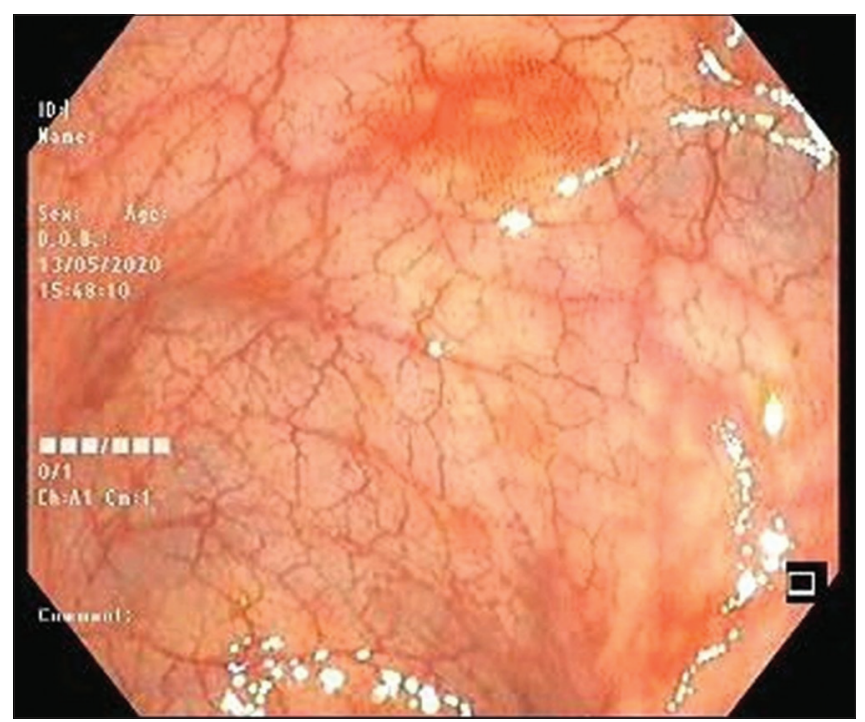

Figure 4: Colonoscopy showing multiple erosions in the rectum, sigmoid, descending, transverse and ascending colon 
pain. There were no further episodes of hematochezia. He was again kept NPO with adequate hydration. Intravenous methylprednisolone was continued at reduced dosage $(0.8 \mathrm{mg} / \mathrm{kg} /$ day). By day 6 of admission, he was asymptomatic. Oral diet was started again, which he tolerated. He was discharged on day 7 on oral prednisolone (1 mg/kg/day), which was tapered and stopped over 1 month. He was also advised strict rest from physical activities for 10 days. He was reviewed every week for 1 month and then monthly for next 3 months; and continued to be asymptomatic.

\section{DISCUSSION}

HSP was first reported by Wilan in 1808. Eduard Heinrich Henoch found a coexistence between purpura and GI haemorrhage in 1874. Johannes Lucas Schonlein, in 1837, reported an association between purpura and arthritis. HSP is less common among adults, and have more of renal involvement. The diagnosis of HSP requires the presence of at least 2 of the following (87.1\% sensitivity and $87.7 \%$ specificity):

- Palpable purpura

- Age $<20$ years at the onset of symptoms

- Bowel angina

- Biopsy showing leukocytoclastic vasculitis.

The GI symptoms are seen in 10 to $20 \%$ of cases. ${ }^{2}$ These include colicky abdominal pain (86\%), occult blood loss $(66 \%)$, vomiting $(40 \%)$, diarrhoea $(20 \%)$ and massive colorectal bleeding $(20 \%) .5$ These symptoms are caused by vasculitis resulting in subserosal and submucosal haemorrhages and the accumulation of fluid in the bowel wall. ${ }^{6,7}$ The duodenum ( $2^{\text {nd }}$ portion), stomach and colon are the commonly involved areas on endoscopic evaluation. ${ }^{8,9}$ The GI lesions are usually irregular ulcers or nodules or hematoma-like protrusions. The CT scan findings include intramural gas in the bowel wall along with decreased or absent bowel wall enhancements, intestinal wall thickening, dilatation of lumen and the presence of intra-abdominal fluid. ${ }^{10}$ Ultrasound scan of the abdomen us used to identify other abdominal pathologies like intussusception and bowel perforation, and abdominal Xray is useful to detect perforation. Arteriography is the gold standard investigation for intestinal ischemia.

The use of corticosteroids in the treatment of HSP is controversial. Positive outcomes have been reported in cases with GI and renal involvement. ${ }^{11,12}$ In a randomized trial, oral prednisone was found to be effective in reducing abdominal pain. ${ }^{12}$ Persistent severe abdominal pain even after initiating corticosteroid therapy is uncommon and should raise the probability of GI complications like bowel ischemia, intussusception and perforation. ${ }^{13,14}$ Intravenous immunoglobulin (IVIG) is an alternative for treatment of steroid-resistant cases. ${ }^{15,16}$ Other treatment options for refractory GI cases include plasma exchange and immunosuppressive drugs like azathioprine, cyclophosphamide and cyclosporine. ${ }^{17}$ Analgesics like acetaminophen, ibuprofen and naproxen, are useful for joint pain and fever. Ranitidine, an $\mathrm{H} 2$ blocker, may be used in patients with moderate GI involvement. ${ }^{18}$ Patients are also advised rest and adequate hydration. Resting with the legs raised may help reduce the development of rash. This is because the petechiae and purpuric lesions tend to develop in dependent areas of the body such as the legs. On exercising the temperature regulation mechanisms within the calf muscles break down, leading to reduced venous return and blood stasis. The end result is inflammation and vascular injury. Moreover, rest is also important for relief of joint pain.

Our patient was an adult, who presented with initial complaints of abdominal pain, vomiting and hematochezia. He later developed purpuric lesions and arthritis. His ASO titers were elevated. His skin biopsy showed leukocytoclastic vasculitis. His abdominal CT was suggestive of HSP and colonic erosions were seen on colonoscopy. He did not have any renal complications. He was treated with corticosteroids, and improved.

\section{CONCLUSION}

HSP is generally a self-limited, multi-systemic IgA mediated small vessel vasculitic disease, commonly affecting children. Adults usually face renal complications. Hematochezia, as one of the initial presentations, is an uncommon. Early diagnosis and treatment of HSP can prevent surgical intervention for GI complications like bowel ischemia, intussusception and perforation.

\section{REFERENCES}

1. Hsu HL, Hsiao $\mathrm{CH}$ and Liu KL. Henoch-Schönlein purpura. Clin Gastroenterol Hepatol 2010; 8(8):e83-e84.

https://doi.org/10.1016/j.cgh.2010.02.011

2. Sharma A, Wanchu A, Kalra N, Singh $S$ and Bambery P. Successful treatment of severe gastrointestinal involvement in adult-onset Henoch-Schönlein purpura. Singapore Med J 2007; 48(11):1047-1050.

3. Blanco R, Martínez-Taboada VM, Rodríguez-Valverde V, García-Fuentes M and González-Gay MA. Henoch-Schönlein purpura in adulthood and childhood: two different expressions of the same syndrome. Arthritis Rheum 1997; 40(5):859-864. https://doi.org/10.1002/art.1780400513

4. Cull DL, Rossario V, Lally KP, Ratner I and Mahour GH. Surgical implications of Henoch-Schönlein purpura. J Pediatr Surg 1990; 25: 741-743.

https://doi.org/10.1016/S0022-3468(05)80009-0 
5. Tancrede-Bohin E, Ochonisky S, Vignon-Pennamen MD, Flageul B, Morel P and Rybojad M. Schönlein-Henoch purpura in adult patients. Predictive factors for IgA glomerulonephritis in a retrospective study of 57 cases. Arch Dermatol 1997; 133(4):438-442.

https://doi.org/10.1001/archderm.1997.03890400034005

6. Novák J, Márki-Zay J, Csiki Z, Sebesi J, Takáts A and Sipka S. Schoenlein-Henoch purpura in adulthood (gastrointestinal manifestation and endoscopy) [in German]. Z Gastroenterol 2001; 39(9):775-782.

https://doi.org/10.1055/s-2001-17195

7. Ashton H, Frenk E, Stevenson CJ and Therapeutics. XV. The management of Henoch-Schonlein purpura. $\mathrm{Br} \mathrm{J}$ Dermatol 1971; 85(2):199-203.

https://doi.org/10.1111/j.1365-2133.1971.tb07216.x

8. Karagozian R, Turbide $C$ and Szilagyi A. Henoch-Schonlein purpura presenting with ileal involvement in an adult. Dig Dis Sci 2004; 49(10):1722-1726.

https://doi.org/10.1023/B:DDAS.0000043392.64347.ea

9. Yoshikawa N, Yamamura F, Akita Y, Sato T and Mitamura K. Gastrointestinal lesions in an adult patient with Henoch-Schönlein purpura. Hepatogastroenterology. 1999; 46(29):2823-2824.

10. Blachar A, Barnes S, Adam SZ, Levy G, Weinstein I, Precel R, et al. Radiologists' performance in the diagnosis of acute intestinal ischemia, using MDCT and specific CT findings, using a variety of CT protocols. Emerg Radiol 2011; 18: 385-394. https://doi.org/10.1007/s10140-011-0965-4

11. García-Porrúa C, Calviño MC, Llorca J, Couselo JM and González-Gay MA. Henoch-Schönlein purpura in children and adults: clinical differences in a defined population. Semin Arthritis Rheum 2002; 32(3):149-156.

https://doi.org/10.1053/sarh.2002.33980
12. Ronkainen $\mathrm{J}$, Koskimies $\mathrm{O}$, Ala-Houhala $\mathrm{M}$, Antikainen $\mathrm{M}$, Merenmies J, Rajantie J, et al. Early prednisone therapy in Henoch-Schönlein purpura: a randomized, double-blind, placebo-controlled trial. J Pediatr 2006; 149(2):241-247.

https://doi.org/10.1016/j.jpeds.2006.03.024

13. Lerkvaleekul B, Treepongkaruna S, Saisawat P, Thanachatchairattana $\mathrm{P}, \quad$ Angkathunyakul $\mathrm{N}$, Ruangwattanapaisarne N, et al. Henoch-Schönlein purpura from vasculitis to intestinal perforation: A case report and literature review. World J Gastroenterol 2016; 22(26):6089-6094. https://doi.org/10.3748/wjg.v22.i26.6089

14. Shiohama T, Kitazawa K, Omura K, Honda A, Kozuki A, Tanaka N, et al. Intussusception and spontaneous ileal perforation in Henoch-Schönlein purpura. Pediatr Int 2008; 50: 709-710. https://doi.org/10.1111/j.1442-200X.2008.02716.x

15. Yang HR, Choi WJ, Ko JS and Seo JK. Intravenous immunoglobulin for severe gastrointestinal manifestation of Henoch-Schonlein purpura refractory to corticosteroid therapy. Korean J Pediatr 2006; 49: 784-789. https://doi.org/10.3345/kjp.2006.49.7.784

16. Weiss PF, Feinstein JA, Luan X, Burnham JM and Feudtner C. Effects of corticosteroid on Henoch-Schönlein purpura: a systematic review. Pediatrics 2007; 120: 1079-1087. https://doi.org/10.1542/peds.2007-0667

17. Başaran Ö, Cakar N, Uncu N, Çelikel BA, Kara A, Cayci FS, et al. Plasma exchange therapy for severe gastrointestinal involvement of Henoch Schönlein purpura in children. Clin Exp Rheumatol 2015; 33: S-176-S-180.

18. Narin N, Akçoral A, Aslin $\mathrm{Ml}$ and Elmastas $\mathrm{H}$. Ranitidine administration in Henoch-Schönlein vasculitis. Acta Paediatr Jpn. 1995; 37(1):37-39. https://doi.org/10.1111/j.1442-200X.1995.tb03682.x

Authors Contribution:

RGM- Concept and design, manuscript preparation, revision of manuscript and treating Physician; PK- Revision of manuscript and treating Gastroenterologist; TA- Resident in-charge.

Work attributed to:

Baby Memorial Hospital, Calicut, Kerala, India.

Orcid ID:

Dr.Robin George Manappallil- (D) http://orcid.org/0000-0003-3973-6800

Source of support: None, Conflicts of Interest: None 